\title{
PRECIFICAÇÃO AO MERCADO DAS EXPORTAÇÕES BRASILEIRAS DE PRODUTOS INDUSTRIALIZADOS
}

\author{
SÉrgio KANNEBLEY JÚNIOR * \\ Leonardo Kiyoshi Kinoshita Assahide ${ }^{\dagger}$
}

\begin{abstract}
Resumo
Este trabalho testa a hipótese de precificação a mercado para as exportadoras brasileiras de produtos manufaturados, utilizando para isso o modelo de Marston (1990), por meio da estimação de modelos de correção de erros em painel. Estimamos elasticidades de precificação a mercado para o longo prazo com valor médio de 0,62 e de 0,18 para o curto prazo. Testamos também a hipótese de precificação assimétrica no curto prazo e verificamos que os exportadores tendem a suavizar o repasse cambial quando a taxa real de câmbio está sobreapreciada e promover um maior repasse cambial em momentos de sobredepreciação cambial.
\end{abstract}

Palavras-chave: Precificação ao mercado; taxa real de câmbio; modelo de correção de erros em painel; exportações.

\begin{abstract}
This article tests for pricing to market hyphotesis for the Brazilian exporters of manufactured goods, using the Marston (1990), through the estimation of panel error correction models. We estimate long and short run elasticities for pricing to the market with an average value of 0.62 and 0.18 respectively. We also tested the hypothesis of asymmetric pricing to market in the short run and found that exporters tend to smooth the exchange rate pass through when the real exchange rate is overvalued and promote greater exchange rate pass through in periods of undervalued real exchange rate.
\end{abstract}

Keywords: Asymmetric pricing to market; Real exchange rate; Error correction models with threshold.

JEL classification: F12, F14, C23

DOI: http://dx.doi .org/10.11606/1980-5330/ea115583

\footnotetext{
* Professor do Departamento de Economia da FEARP-USP. E-mail: skj.usp@gmail.com

${ }^{\dagger}$ Mestre em Economia Aplicada pela FEARP-USP.
} 


\section{Introdução}

Sob a hipótese de mercados imperfeitos, os exportadores podem ajustar suas margens de lucro a fim de suavizar os impactos das variações cambiais sobre os preços, havendo a possibilidade para ajustamentos incompletos dos preços em moeda estrangeira. Segundo Krugman (1986), as evidências de repasse cambial incompleto seriam resultado de uma prática de discriminação de preços internacionais induzida pelas variações da taxa de câmbio, denominada de precificação ao mercado. As recentes flutuações das taxas de câmbio renovam o interesse em seus impactos sobre a competitividade das exportações brasileiras de produtos manufaturados e a investigação da hipótese de precificação ao mercado para o caso brasileiro.

De particular interesse sobre a competividade dos bens comercializáveis, está a discriminação entre os mercados doméstico e estrangeiro. Este artigo tem o objetivo de medir o repasse cambial aos preços de exportações em relação aos preços de bens similares destinados ao mercado doméstico. Contudo, a estimação desse grau de repasse envolve problemas de erro de medida e endogeneidade gerados pela não observabilidade completa dos custos marginais das firmas e pelo efeito das variações cambiais sobre a produção e sobre os custos dos insumos importados, que impactam sobre o custo marginal. Com isso, para se obter essa medida de repasse cambial é necessário separar os efeitos da variação da taxa de câmbio, que induzem a mudança do markup, de seus efeitos causadores de variações nos custos.

Marston (1990) desenvolve um modelo teórico em que uma firma monopolista discrimina preços entre os mercados doméstico e internacional, demonstrando que a elasticidade de precificação ao mercado depende da convexidade da curva de demanda no mercado exportador e de variações dos custos marginais decorrentes das variações do produto. Um dos méritos do trabalho de Marston (1990) encontra-se na estratégia de identificação do parâmetro de elasticidade de precificação ao mercado, baseada no fato de o custo marginal ser um fator comum ao produto destinado aos mercados doméstico e internacional, o que permite isolar seu efeito e estimar a elasticidade de precificação ao mercado como a resposta do relativo de preços entre o mercado externo e doméstico à variação da taxa real de câmbio. Knetter (1989) também desenvolve uma estratégia de identificação similar, buscando separar os efeitos das variações cambiais sobre as variações de custos e do markup por meio da estimação de um modelo com efeitos fixos para os preços de exportações. Em nosso trabalho, optamos por utilizar o modelo de Marston (1990) em razão do mesmo permitir a obtenção de elasticidades de precificação ao mercado no curto e no longo prazo, fornecendo uma interpretação direta do parâmetro em função das variações da taxa real de câmbio, além de fornecer estimativas de parâmetros para os demais determinantes da formação de preços em mercados sob concorrência imperfeita.

Evidências internacionais de precificação ao mercado foram produzidas por diversos autores. Knetter (1989) demonstra que enquanto os exportadores alemães tendem a estabilizar os preços em dólar no mercado americano, os exportadores americanos são pouco sensíveis à taxa de câmbio, ajustando os preços na moeda do país estrangeiro de forma a amplificar o impacto das variações cambiais. Gagnon \& Knetter (1995), ao analisar especificamente as exportações de automóveis por parte dos produtores japoneseses, alemães e americanos, evidenciam diferentes comportamentos em termos de ajusta- 
mento de suas margens de lucro, sendo os exportadores japoneses aqueles que praticam maior ajustamento de suas margens de lucro nesse mercado. Marston (1990), ao procurar explicar a margem entre os preços de exportação em Iene e os preços domésticos para um amplo conjunto de bens, incluindo bens de transporte e eletrônicos, demonstra que as firmas japonesas respondem a variações da taxa real de câmbio precificando a mercado, variando o relativo de preços de exportações em relação aos preços domésticos em resposta as variações da taxa real de câmbio. No entanto, ao avaliar a possibilidade de efeitos assimétricos da taxa de câmbio, conclui que para a maioria dos produtos analisados que a precificação à mercado seria invariante à direção da variação da taxa de câmbio. Gil-Pareja (1995) testou potenciais assimetrias no comportamento de precificação ao mercado para indústrias exportadoras em diversos membros da União Europeia entre 1986 e 1994. Esse autor demonstrou que a precificação para mercado é um comportamento pervasivo, em concordância com os resultados de Knetter (1994), não rejeitando também a hipótese nula de simetria para a maior parte dos produtos analisados. No entanto, Byrne et al. (2013) argumentam que as repostas de preços de exportações à taxa de câmbio pode ser instável no tempo, associando períodos de alta volatilidade cambial a maiores ajustamentos da margem de lucro bruta a fim de mitigar efeitos adversos sobre a demanda, com evidências favoráveis a essa hipótese ao analisar o comportamento de preços das exportações do Reino Unido.

Com relação à precificação das exportações brasileiras, os trabalhos de Kannebley Júnior (2000) e Ferreira \& Sansó (1999) estimam o repasse cambial aos preços de exportação em moeda estrangeira e concluem de modo similar que o repasse é bastante baixo, principalmente em períodos de alta inflação como ocorreu posteriormente ao fracasso do Plano Cruzado até meados dos anos de 1990. Por outro lado, Correa (2012) produziu uma análise do grau de repasse cambial em nível setorial para o período de 1995 a 2005, concluindo que o repasse do câmbio aos preços das exportações é incompleto, com prevalência de elasticidades no intervalo de 0,45 a 0,70. Especificamente com relação ao grau de precificação ao mercado, Barroso (2012), utilizando a especificação com efeitos fixos proposta por Knetter (1989) em uma abordagem de cointegração em painel, apura uma elasticidade média de precificação ao mercado de 0,58 . Seus resultados também são distintos por grau de intensidade tecnológica, apontando uma relação positiva entre o repasse cambial e o grau de intensidade tecnológica do setor. Da Silva Correa et al. (2016) apresentam uma pesquisa sobre práticas de precificação das firmas brasileiras em que destaca que a formação de preços baseada em uma regra de markup é prática usual nas firmas, sendo que firmas exportadoras, em sua maioria (58\%), fixam seus preços em moeda doméstica (reais) e convertem seu preço na moeda do país estrangeiro. Para os exportadores, os custos de insumos intermediários e a taxa de câmbio são os principais determinantes das variações de preços das exportações. Essas práticas são consistentes com os pressupostos teóricos que são utilizados nos modelos de precificação em mercados, o que reforça o interesse na condução de nossa pesquisa.

No presente trabalho, fazemos uso de uma base de dados inédita que conta com informações de exportações para 26 setores industriais, destinados a 6 países importadores distintos durante o período de 1999 a 2012. Esse período, além de não ter sido analisado anteriormente, conta com uma relativa estabilidade macroeconômica e uma estabilidade do regime cambial poucas vezes registradas em outros estudos sobre tema no Brasil. Diferentemente da maior 
parte da literatura sobre o tema, são estimados modelos de correção de erros em painel, obtendo-se estimativas de curto e longo prazo para a elasticidade de precificação ao mercado. Nossos resultados indicam que a elasticidade de precificação ao mercado está entre 0,6 e 0,7 para as exportações de produtos industrializados no longo prazo e entre 0,2 e 0,3 para o curto prazo. Os grupos de setores com maior grau de precificação são os setores produtores de bens de capital e de bens de consumo não duráveis. Também verificamos, por meio da estimação de modelos não lineares, que os exportadores apresentam um comportamento assimétrico com relação à taxa de câmbio, tendendo a suavizar o repasse cambial quando a taxa real de câmbio está sobreapreciada e promover um maior repasse cambial em momentos de sobredepreciação cambial. Utilizando medidas alternativas de desalinhamento cambial obtivemos elasticidades entre 0,3 e 0,5 para períodos de sobredepreciação e de elasticidades entre zero e 0,2 em períodos de sobreapreciação.

Além desta introdução o artigo ainda conta com mais estas cinco seções, sendo a primeira onde se apresenta o modelo teórico proposto por Marston (1990). A segunda seção discute a implementação empírica desse modelo com dados em painel, além de apresentar os métodos de estimação utilizados no estudo. Na terceita seção, é apresentada a base de dados utilizada, além de fatos estilizados sobre a relação entre o relativo de preços e medidas de taxa de câmbio de real. Na quarta seção são discutidos resultados no agregado e desagregados segundo categorias de uso, além da estimação de modelos não lineares sob a suposição de precificação ao mercado assimétrica no curto prazo. Por fim, na quinta seção são tecidas considerações finais sobre as estimações e relações com a literatura de formação de preços.

\section{Modelo de precificação ao mercado}

A fim de demonstrar o comportamento de precificação ao mercado, Marston (1990) elabora um modelo considerando uma firma monopolística em uma determinada indústria que produz no seu próprio país e vende tanto para o mercado doméstico a um preço $P_{j t}$, como para o mercado externo a um preço $P_{j t}^{*}$, sendo $S_{t}$ a taxa de câmbio, $P_{t}$ e $P_{t}^{*}$ os respectivos níveis gerais de preços. A firma alterará a razão entre o preço externo e preço doméstico, $X_{j t}=\left(S_{t} P_{j t}^{*} P_{j t}\right)$, em razão de variações cambiais, variações dos custos ou da demanda. Assumese que a firma tenha uma função de custos, $c($.) e faça face às funções de demanda doméstica $Q\left(\right.$.) e demanda externa $Q^{*}($.$) . Definindo produto doméstico$ $Y_{t}$, produto externo $Y_{t}^{*}$, salários $W_{t}$ e preços das matérias-primas $P_{t}^{m}$, a função lucro $\pi_{j t}$ é dada por:

$$
\pi_{j t}=P_{j t} Q\left(\frac{P_{j t}}{P_{t}}, Y_{t}\right)+S_{t} P_{j t}^{*} Q^{*}\left(\frac{P_{j t}^{*}}{P_{t}^{*}}, Y_{t}^{*}\right)-c\left\{\left[Q(.)+Q^{*}(.)\right], W_{t}, P_{t}^{m}\right\}
$$

As condições de primeira ordem são dadas por:

$$
\begin{aligned}
& \frac{P_{j t} Q_{1}}{P_{t}}+Q(.)-\frac{C_{1} Q_{1}}{P_{t}}=0 \\
& \frac{P_{j t}^{*} Q_{1}^{*}}{P_{t}^{*}}+Q^{*}(.)-\frac{C_{1}^{*} Q_{1}^{*}}{P_{t}^{*}}=0
\end{aligned}
$$

o que leva às expressões escritas em termos dos markups: 


$$
\begin{aligned}
& P_{j t}=C_{1}(.) M\left(\frac{P_{j t}}{P_{t}}, Y_{t}\right) \\
& S_{t} P_{j t}^{*}=C_{1}(.) M^{*}\left(\frac{P_{j t}^{*}}{P_{t}^{*}}, Y_{t}^{*}\right)
\end{aligned}
$$

em que $C_{1}$ é a função de custo marginal, sendo o Subscrito 1 indicando a derivada da função custo com relação ao primeiro argumento da função, $Q_{1}$ é a derivada da função de demanda com relação ao primeiro argumento, sendo o mesmo caso para $Q_{1}^{*}$. M(.) é o markup do preço doméstico sobre o custo marginal e $M^{*}$ (.) é o markup do preço para exportação sobre o custo marginal (expresso em moeda doméstica). Os markups podem ser escritos em função das elasticidades-preço das demandas doméstica e externa, $\mu=-\frac{Q_{1}}{Q} \frac{P_{j t}}{P_{t}}$ e $\mu^{*}=$ $-\frac{Q_{1}^{*}}{Q^{*}} P_{j t}^{*}$, respectivamente. Com isso tem-se $M()=.\mu /(\mu-1)$ e $M^{*}()=.\mu^{*} /\left(\mu^{*}-1\right)$.

Consequentemente, os preços no mercado doméstico e externo não são independentes, na medida em que estão ligados por meio de alterações que ocorrem no custo marginal $C_{1}($.$) . Como o custo marginal é um fator comum$ a ambos mercados, então $X_{j t}=\left(M^{*}() M.().\right)$, de modo que alterações no relativo de preços devido a variações cambiais ocorrerão por meio das diferentes respostas das elasticidades-preço da demanda a essas variações.

As respostas dos preços em relação às mudanças na taxa de câmbio dependem de dois fatores: convexidade da curva da demanda no mercado e das alterações no custo marginal decorrente da quantidade de produção. Por meio da diferenciação total das condições de primeira ordem, é possível obter a elasticidade do preço externo em relação à taxa de câmbio $\left(\beta_{1}\right)$, i.e. o repasse cambial ao preço de exportação (externo) ${ }^{1}$. De forma análoga, é possível obter o repasse cambial ao preço doméstico $\left(\beta_{2}\right)$, ambos dados por:

$$
\beta_{1}=\frac{\left(\frac{\partial P_{j t}^{*}}{P_{j t}^{*}}\right)}{\left(\frac{\partial S_{t}}{S_{t}}\right)}=-\frac{H_{11} S_{t}}{|H|}<0 \beta_{2}=\frac{\left(\frac{\partial P_{j t}}{P_{j t}}\right)}{\left(\frac{\partial S_{t}}{S_{t}}\right)}=-\frac{t\left[M^{*}(.) C_{11} Q_{1}^{*}\right] P_{t}^{*}}{|H|} \geq 0
$$

sendo:

$$
\begin{array}{r}
H_{11}=1-\left(C_{1} M_{1}\right) / P_{t}-\left(\left(M(.) C_{11} Q_{1}\right)\right) / P_{t} ; \\
H_{22}=S_{t}-\left(C_{1} M_{1}^{*}\right) / P_{t}^{*}-\left(M^{*}(.) C_{11} Q_{1}^{*}\right) / P_{t}^{*} \\
\text { e }|H|=H_{11} H_{22}-\left[M(.) M^{*}(.)\left(C_{11}\right)^{2} Q_{1} Q_{1}^{*}\right] /\left(P_{t} P_{t}^{*}\right)
\end{array}
$$

em que $C_{11}$ é a derivada do custo marginal em relação ao produto. Sendo $P_{j t}^{*}=\frac{C_{1}}{S_{t}} M^{*}\left(\frac{P_{j t}^{*}}{P_{t}^{*}}, Y_{t}^{*}\right)$, a depreciação cambial representa uma redução nos custos. Usando o fato que $C_{1}>0$ e que $Q_{1}<0$ Marston (1990) demonstra que $H_{11}>0$ e por raciocínio semelhante que $H_{22}>0$, tal que $|H|>0$ e com isso $\beta_{1}<0$. $\mathrm{O}$ repasse cambial aos preços de exportação somente será completo $\left(\beta_{1}=-1\right)$ se os custos marginais forem constantes $\left(C_{11}=0\right)$ e a curva de demanda por elasticidade constante $\left(\tau^{*}=0\right)$ como veremos a seguir ${ }^{2}$. A depreciação da taxa

\footnotetext{
${ }^{1}$ Os graus de repasse foram derivados a partir de:

$$
\left[\begin{array}{cc}
1-\frac{M_{1} C_{11} Q_{1}}{P_{t}}-\frac{C_{1} M_{1}}{P_{t}} & \frac{M C_{11} Q_{1}^{*}}{P_{t}^{*}} \\
-\frac{M^{*} C_{11} Q_{1}^{*}}{P_{t}} & S_{t}-\frac{M_{1}^{*} C_{11} Q_{1}^{*}}{P_{t}^{*}}-\frac{C_{1} M_{1}^{*}}{P_{t}^{*}}
\end{array}\right]\left[\begin{array}{c}
d P_{j t} \\
d P_{j t}^{*}
\end{array}\right]=\left[\begin{array}{c}
0 \\
P_{j t}^{*} d S_{t}
\end{array}\right]
$$

${ }^{2}$ No caso de custos marginais constantes: $\beta_{1}=\frac{-S_{t}}{S_{t}-\left(M_{1}^{*} P_{i t}^{*}\right) /\left(M^{*}(.) P_{t}^{*}\right)}$.
} 
de câmbio afetará o preço doméstico caso o custo marginal varie com a produção, isto é, $C_{11}>0$. No caso de custos marginais constantes, $C_{11}=0$, o preço doméstico não responderá à variação cambial. Assim sendo, dado que $Q_{1}^{*}<0$ então $\beta_{2} \geq 0$. Por fim, sendo $\ln X_{j t}=\ln S_{j t}+\ln P_{j t}-\ln P_{j t}$, a elasticidade do relativo de preços à taxa de câmbio, $\alpha_{1}$, representa o efeito de precificação ao mercado:

$$
\alpha_{1}=\frac{\partial X_{j t}}{X_{j t}}=1+\beta_{1}-\beta_{2}=\frac{-\tau^{*} S_{t} H_{11}+\tau\left(\frac{M^{*}(.) C_{11} Q_{1}^{*}}{P_{t}^{*}}\right)}{|H|}
$$

em que $\tau$ é a elasticidade do markup doméstico com relação ao preço doméstico; e $\tau^{*}$ é a elasticidade do markup no mercado externo com relação ao preço externo, definidas como: $\tau=\left(M_{1} P_{i t}\right) /\left(M(.) P_{t}\right)$ e $\tau^{*}=\left(M_{1}^{*} P_{i t}^{*}\right) /\left(M^{*}(.) P_{t}^{*}\right)^{3}$. Essas elasticidades podem ser positivas, negativas, ou nulas na medida em que dependem das respectivas curvas de demanda. Portanto, $\alpha_{1}$ dependerá dos sinais de $\tau$ e $\tau^{*}$, dado que $|H|>0$. Restringindo-se à hipótese de que $C_{11}>0$, é possível observar dois casos principais em relação às elasticidades dos markups. Quando se supõe funções de demanda com elasticidades constantes, então os markups são constantes, suas elasticidades em relação aos preços são nulas $\left(\tau=\tau^{*}=0\right)$ e com isso $\alpha_{1}=0$. Isto é, os preços (internos e externos) são afetados apenas pelas variações do custo marginal comum a ambos, de modo que o relativo de preços permanece inalterado e não há precificação ao mercado ${ }^{4}$. Sendo assim, para que ocorra precificação ao mercado os markups precisam responder a variações nos preços. Dessa forma, um aumento dos preços reduz o markup sobre os custos marginais e uma queda nos preços aumenta o markup $\left(\tau, \tau^{*}<0\right)$. Isso se dá com qualquer curva de demanda mais linear do que uma curva de demanda com elasticidade constante. Nesse caso uma depreciação da moeda doméstica $\left(d S_{t}>0\right)$ diminui os preços de exportação (na moeda do mercado importador), aumentando o markup. Com o aumento do markup a redução do preço externo é menor que do que a depreciação cambial, ou seja, o repasse cambial é incompleto $\left(-1<\beta_{1}<0\right)$. Se o preço for convertido para a moeda do exportador, o seu valor será maior em termos percentuais $\left(0<1+\beta_{1}<1\right)$. Pelo lado dos preços domésticos, se os custos marginais aumentarem com o aumento da produção, os preços domésticos aumentam com a depreciação da moeda $\left(\beta_{2}>0\right)$, havendo em consequência uma redução do markup. Nesse caso a margem entre os preços estrangeiros e domésticos deve aumentar, ou seja, a elasticidade da precificação ao mercado será positiva, porém inferior à unidade $\left(0<\alpha_{1}<1\right)^{5}$. Para determinar os demais fatores que afetam os preços relativos, uma expressão em forma reduzida é obtida por meio da diferenciação total das condições de primeira ordem Equação (2), resolvendo-se para $d X_{j t} / X_{j t}$ :

\footnotetext{
${ }^{3}$ Esse resultado é obtido a partir de $\alpha=\frac{|H|-H_{11} S_{t}-\frac{Q_{1}^{*} C_{11} M_{1}^{*}}{P_{t}^{*}}}{|H|}$, usando o fato de que $C_{1}=\frac{P_{i t}}{M}=$ $\frac{P_{i t}^{*}}{M^{*}}$, em que $M_{1}$ e $M_{1}^{*}$ são as derivadas dos markups com relação ao relativo de preços, o primeiro argumento das funções.

${ }^{4} \mathrm{O}$ mesmo resultado seria obtido com $C=0$, pois $\alpha=1+\beta=1-1=0$.

${ }^{5}$ De fato, desde que $\tau^{*}<0$, mesmo que $C_{11}=0$, então $0<\alpha_{1}<1$, mas nesse caso com $\beta_{2}=$ 0 . O caso em que as elasticidades do markup são positivas são também analisadas pelo autor $\left(\tau, \tau^{*}>0\right)$, mas sendo inconsistentes com os fatos estilizados de repasse cambial incompleto, não são reportadas aqui. Para o leitor interessado ver Marston (1990).
} 


$$
\frac{d X_{j t}}{X_{j t}}=\alpha_{1}\left(\frac{d R_{t}}{R_{t}}\right)+\alpha_{2}\left(\frac{d Y_{t}^{*}}{Y_{t}^{*}}\right)+\alpha_{3}\left(\frac{d Y_{t}}{Y_{t}}\right)+\alpha_{4}\left[\frac{\left(\frac{d W_{t}}{P_{t}}\right)}{\left(\frac{W_{t}}{P_{t}}\right)}\right]+\alpha_{5}\left[\frac{\left(\frac{d P_{t}^{m}}{P_{t}}\right)}{\left(\frac{P_{t}^{m}}{P_{t}}\right)}\right]
$$

em que $R_{t}=\left(S_{t} P_{t}^{*}\right) / P_{t}$ é a medida agregada de relativos de preços, isto é, de taxa de câmbio real; $Y_{t}^{*}$ é o produto interno bruto real; $Y_{t}$ a produção doméstica; $W_{t} / P_{t}$ o salário real no país produtor e $P_{t}^{m} / P_{t}$ o nível de preço real das matérias-primas. A influência dos níveis gerais de preços ocorre por meio das respectivas funções de demanda. As elasticidades de $X_{i t}$ com relação aos dois níveis gerais de preços, $P_{t}^{*}$ e $P_{t}$, seguem como:

$$
\begin{array}{r}
\frac{d X_{i t}}{d P_{t}^{*}} \frac{P_{t}^{*}}{X_{i t}}=\alpha_{1} \\
\frac{d X_{i t}}{d P_{t}} \frac{P_{t}}{X_{i t}}=-\alpha_{1}-\frac{S_{t}}{|H|}\left(\tau-\tau^{*}\right)
\end{array}
$$

Ou seja, o aumento no nível geral de preços estrangeiro tem efeito igual a uma desvalorização cambial. Já o aumento no nível geral de preços doméstico tem um efeito maior, ou menor, ao de uma desvalorização cambial dependendo das diferenças entre as elasticidades do markup com relação aos preços, $\left(\tau-\tau^{*}\right)$. Os parâmetros $\alpha_{2}$ e $\alpha_{3}$ representam as elasticidades-renda sobre o relativo de preços, mas seus impactos dependerão das diferenças entre as elasticidades do markup com relação aos preços, $\left(\tau-\tau^{*}\right)$, e das elasticidades dos markups com relação à renda. O autor tem dificuldade de predizer o sinal e a magnitude desses parâmetros em razão dos seus diversos componentes. Os parâmetros $\alpha_{4}$ e $\alpha_{5}$ refletem os efeitos de alterações de preços relativos dos fatores de produção. Suas respectivas expressões são dadas por:

$$
\begin{aligned}
& \alpha_{4}=\left(\tau-\tau^{*}\right) \frac{\left[C_{12} W_{t} S_{t}\right]}{C_{1}|H|} \geq \mathrm{ou} \leq 0 \\
& \alpha_{5}=\left(\tau-\tau^{*}\right) \frac{\left[C_{13} P_{t}^{m} S_{t}\right]}{C_{1}|H|} \geq \mathrm{ou} \leq 0
\end{aligned}
$$

e serão nulos caso em que as funções de demanda tenham a mesma curvatura $\left(\tau=\tau^{*}\right)$, ou então sejam curvas com elasticidade constante $\left(\tau=\tau^{*}=0\right)$. O que fica notório é que o impacto dos preços dos fatores de produção somente será não nulo caso as curvaturas das funções de demanda sejam distintas. Assim, a menos que o comportamento da demanda seja extremamente diferente nos dois mercados essas elasticidades devem ter magnitude reduzida. Por ser a função de custos marginais homogênea de grau nos preços dos insumos é possível escrever $\frac{d X_{i t}}{P_{t}} \frac{d P_{t}}{X_{i t}}=-\alpha_{1}-\alpha_{4}-\alpha_{5}$, o que explica a Equação (6) estar expressa em termos reais e $\alpha_{1}$ ser o principal parâmetro de interesse, representando a elasticidade de precificação de mercado $^{6}$.

Em suma, esse modelo permite racionalizar o fato estilizado do grau de repasse cambial incompleto aos preços de exportações, bem como a distinção entre o grau de repasse cambial e o grau de precificação ao mercado entre os mercados doméstico e externo.

\footnotetext{
${ }^{6}$ Isto é, pela Lei de Euler: $C_{W}+C_{P}^{m}=C$, fazendo com $\alpha+\alpha=S_{t}\left(\tau-\tau^{*}\right)$.
} 


\section{Especificação para teste da hipótese de precificação ao mercado}

A contrapartida empírica para a Equação (6) é uma versão log-linear dada por:

$$
\Delta x_{j t}=\alpha_{1} \Delta r_{t}+\alpha_{2} \Delta y_{t}^{*}+\alpha_{3} \Delta y_{t}+\alpha_{4} \Delta \frac{w_{t}}{p_{t}}+\alpha_{5} \Delta \frac{p_{t}^{m}}{p_{t}}
$$

em que as variáveis em letras minúsculas correspondem ao logaritmo da variável original, isto é, $\Delta x_{j t}=\ln \left(X_{j t}\right)-\ln \left(X_{j t-1}\right)$. Admitindo a possibilidade de que firmas fixem os preços externos em moeda internacional com base em informa- ções disponíveis em $(t-1), q_{j t}$ e $p_{j t}$ estariam pré estabelecidos. Nesse caso Marston (1990) argumenta que o relativo de preços também seria afetado por desvios não previstos da taxa nominal de câmbio, ou seja:

$$
\Delta x_{j t}=\left(\Delta s_{t}-E_{t-1} \Delta s_{t}\right) \alpha_{1} \Delta r_{t}+\alpha_{2} \Delta y_{t}^{*}+\alpha_{3} \Delta y_{t}+\alpha_{4} \Delta \frac{w_{t}}{p_{t}}+\alpha_{5} \Delta \frac{p_{t}^{m}}{p_{t}}
$$

Sob a hipótese de que a taxa nominal de câmbio segue um processo de caminho aleatório (random walk), em que $E_{t-1} s_{t}=s_{t-1}$, então $E_{t-1} \Delta s_{t}=\left(E_{t-1} s_{t}-\right.$ $\left.E_{t-2} s_{t-1}\right)=\left(s_{t-1}-s_{t-2}\right)$, fazendo com que o erro expectacional para a taxa nominal de câmbio seja dada pela diferença entre a variação do último período e a variação do período anterior, $\left(\Delta s_{t}-\Delta s_{t-1}\right)$. Essa variável é adicionada apenas na especificação de curto prazo na medida em que seu efeito é transitório e assim como nos resultados estimados pelo autor, é esperado que tanto a taxa real de câmbio como a surpresa cambial possuam efeitos positivos nos preços relativos $^{7}$. Entretanto, a especificação dada pela Equação (10) desconsidera a possibilidade de relações de longo prazo entre as variáveis. De fato, a solução empírica dada por Marston (1990) para esse problema, ao tratar os efeitos dos erros expectacionais sobre o comportamento do relativo de preços e considerar a possível heterogeneidade na precificação das exportações derivada da própria heterogeneidade dos tipos de bens, foi incorporar uma dinâmica ao relativo de preços por meio de inclusão de defasagens para as variáveis do lado direito da equação. No entanto, caso as variáveis sejam não estacionárias, é possível admitir que as variáveis inclusas na Equação (6) definam uma relação de cointegração. Nesse caso, a representação empírica de Marston (1990) apresentaria um erro de especificação devido à não inclusão do desvio dessa relação de longo prazo, que deveria ser expressa por meio de um modelo de correção de erros. Adicionando uma terceira dimensão às variáveis, ao se considerar que um produtor doméstico pode exportar para mais de um país, então o mesmo modelo poderia ser utilizado para representar a precificação entre o país doméstico e o país estrangeiro $i$. Partindo de uma relação dinâmica entre o relativo de preços e as demais variáveis explicativas representada por um modelo autoregressivo de defasagens distribuídas, $\operatorname{ARDL}(p, q)$, em que $x_{i j t}$ corresponde ao relativo de preços do setor $j$, entre o

\footnotetext{
${ }^{7}$ Supondo que não há precificação a mercado, e os $\alpha$ 's sejam iguais a zero, então o $\Delta x$ é afetado somente pelas surpresas cambiais $\left(\Delta s_{t}-\Delta s_{t-1}\right)$. Se não houver surpresa cambial entre os períodos $t-2$ e $t-1$, então a variação nos preços relativos será igual a surpresa cambial entre os períodos $t-1$ e $t$, isto é, $\Delta x_{j t}=\Delta s_{t}$. No entanto, se não houver surpresa cambial entre $t$ e $t+1$ também não haverá efeito em $\Delta x_{j t+1}$ fazendo com que $x_{j t+1}=x_{j t}$, de modo que a alteração não esperada da taxa nominal de câmbio entre $t-1$ e $t$ possua apenas um efeito transitório sobre o relativo de preços.
} 
país doméstico e o país $i$ no tempo corrente $t$ e $z_{i} t=y_{i} t, y_{i} t, p_{i} t, p_{i} t$. Assim sendo, temos o modelo dinâmico:

$$
x_{i j t}=\sum_{k=1}^{p} \lambda_{i j k} x_{i j t-k}+\sum_{k=1}^{q} \delta_{i j k}^{\prime} z_{i t-k}+\mu_{i}+\epsilon_{i j t}
$$

De acordo com Pesaran et al. (1999) a partir de um modelo ARDL, é possível reparametrizá-lo e obter o termo:

$$
e c m_{i j t}=x_{i j t-1}-\theta_{1} r_{i t}-\theta_{2} y_{i t}^{*}-\theta_{3} y_{i t}-\theta_{4} c_{j} t
$$

em que $i$ indica o país, $j$ o setor e $t$ o tempo; e $c_{j t}$ é o custo setorial (a variável foi utilizada agregando as informações das variáveis de nível real dos salários e preços reais das matérias-primas). O termo de longo prazo será incluído como uma das variáveis explicativas do modelo. Dessa forma, será estimada a seguinte equação:

$$
\Delta x_{i j t}=\sum_{k=1}^{p-1} \lambda_{i j k}^{*} x_{i j t-k-1}+\sum_{k=1}^{q} \delta_{i j k}^{*} \Delta z_{i j t-k}+\phi_{i j} e c m_{i j t}+\mu_{i}+\epsilon_{i j t}
$$

A partir dessa formulação em um modelo de correção de erros em painel é possível se distinguir os parâmetros de curto e longo prazo do modelo. Por se tratar de elasticidades, conforme é previsto pela teoria econômica, os parâmetros de longo prazo devem possuir magnitudes superiores aos seus correspondentes de curto prazo. Com relação às variáveis de controle (renda do país importador, nível da produção industrial, nível dos salários reais e nível dos preços reais das matérias-primas), é esperado que a renda do país importador possua efeito positivo, pois um aumento da renda representaria um aumento de demanda externa. Como o nível de produção setorial está associado à renda e à demanda interna, a produção doméstica deve ter um efeito negativo nos preços relativos. Os custos (salários e preços das matérias-primas) aumentam os preços internos e externos, dessa forma, o sinal do coeficiente dependerá da capacidade de discriminação dos preços em cada setor, o que estaria relacionado às elasticidades-preço do markup conforme mencionado anteriormente na seção teórica. A literatura sobre a estimativa de painéis dinâmicos heterogêneos em que, tanto a dimensão em cross-section, como a dimensão temporal, são grandes, apresenta diversas abordagens para a estimativa da Equação (14). Em um extremo, o estimador de efeitos fixos poderia ser aplicado aos conjuntos de séries temporais agrupadas e somente os interceptos seriam permitidos diferir entre os grupos (estimador Pooled). Esse estimador é inconsistente caso a hipótese de que os coeficientes não sejam iguais, algo bastante provável em um caso de grupos com três dimensões. No outro extremo, o modelo pode ser estimado separadamente para cada grupo de país e setor, e uma média aritmética simples dos coeficientes ser calculada. Este é o estimador Mean Group (MG) proposto por Pesaran \& Smith (1995). Com esse estimador, tanto os coeficientes de inclinação como os interceptos e as variâncias dos erros são permitidos variar para cada grupo, garantindo-se a consistência das estimativas mesmo que os coeficientes não sejam iguais. Este estimador não leva em conta a possibilidade de que alguns parâmetros podem ser os mesmos para todos os grupos e pode ter um custo em termos de eficiência no caso das restrições de igualdade serem válidas. Em um caso intermediário, Pesaran et al. 
(1999) propõem o estimador Pooled Mean Group (PMG) que combina agrupamento e média. Esse estimador permite que os coeficientes de curto prazo, intercepto e variância dos erros variem entre os grupos, restringindo os coeficientes de longo prazo a serem os mesmos para todos os grupos. As estimações são realizadas por máximo verossimilhança devido à não linearidade dos parâmetros. No entanto, é importante lembrar que os estimadores PMG e MG assumem que os regressores são fracamente exógenos. A fim de assegurar estimativas consistentes na eventualidade de endogeneidade de algumas das variáveis consideradas no modelo também serão realizadas estimativas de equações de longo prazo por meio dos estimadores Pooled e Mean Grouped Dynamic Ordinary Least Squares (DOLS) propostos por Pedroni (2001a), Pooled e Mean Grouped - Fully Modified Ordinary Least Squares (FMOLS) propostos por Pedroni $(2001 b)$. Os estimadores DOLS e FMOLS consideram a autocorrelação dos erros, além de permitir a presença de variáveis endógenas. Uma das diferenças entre eles consiste no fato do DOLS controlar o efeito do feedback endógeno de forma paramétrica, enquanto o FMOLS controla de modo não paramétrico. Os resultados apresentados serão produzidos por esses diferentes estimadores, com exceção do estimador Pooled, que impõe restrições excessivas ao modelo.

\section{Bases de dados e fatos estilizados}

Uma das inovações deste trabalho foi testar a hipótese de precificação ao mercado, utilizando uma base de dados em painel composta por 3 dimensões (país $i$, setor industrial $j$ e tempo $t$ ). A base de dados possui para a variável dependente, 6.440 observações, em 115 dimensões cross-section, sendo 56 períodos. Os dados trimestrais estão compreendidos entre o primeiro trimestre de 1999 e o quarto trimestre de 2012 para 26 setores industriais, classificados segundo a Matriz de Relações Industriais. São analisadas as exportações brasileiras para seis mercados: Argentina, Chile, China, Estados Unidos, Japão e México. Os 6 mercados importadores analisados correspondem à aproximadamente $45 \%$ das exportações de produtos manufaturados no período, sendo $22 \%$ para a Argentina, 3\% para o Chile, 2\% para a China, 13\% nos Estados Unidos, $1 \%$ para o Japão e $4 \%$ para o México. O relativo de preços $X_{i, j, t}$ difere de acordo com o país $i$, a indústria $j$ e ao longo do tempo $t$, sendo calculada a partir da razão entre os preços setoriais de exportação por país da FUNCEX (Fundação Centro de Estudos do Comércio Exterior - www. funcexdata.com.br), convertida em moeda nacional (Real) pela taxa nominal de câmbio Real-Dólar, e os Índices de Preços ao Produtor Amplo (IPA-FGV) por setor industrial. Para cada país foram utilizadas as medidas de taxa real de câmbio, $R_{i, t}$, calculadas pela FUNCEX (Fundação de Estudos do Comércio Exterior) por meio da razão entre o correspondente índice de preços atacadista externo, corrigido pela taxa nominal de câmbio, e o índice de preços atacadista doméstico (IPA-DI da FGV), de onde também foram extraídas as informações de taxa de câmbio nominal $s_{i, t}$ entre os seis países e a moeda nacional. Os dados para a variável de produto interno bruto real do país importador $i, Y_{i, t}$, foram extraídas do banco de dados da OCDE (Organização para a Cooperação e Desenvolvimento Econômico). Para a produção doméstica foi utilizado o índice de produção trimestral $Y_{j, t}$ calculado pelo IBGE (Instituto Brasileiro de Geografia e Estatística). Já o índice de custo $C_{j, t}$, foi obtido por meio da relação entre razão 
entre o índice de preços de exportação e o índice de rentabilidade da FUNCEX para cada setor ${ }^{8}$. As estatísticas descritivas das variáveis em logaritmo são apresentadas na Tabela 1. Pode-se observar que a quantidade de observações também não é idêntica, havendo diferenças nos números de observações por cross-section.

A fim de exemplificar a associação entre o relativo de preços e o indicador de taxa real de câmbio são apresentadas na Figura 1 os gráficos por país para o setor da siderurgia ${ }^{9}$. Pode-se observar que há uma forte associação nos movimentos dos preços relativos e da taxa real de câmbio, principalmente para as exportações para a Argentina e para os Estados Unidos. Na Tabela 2, essa associação é demonstrada estatisticamente por meio da estimação de modelos autoregressivos de defasagem distribuída de ordem $1, \operatorname{ARDL}(1,1)$ em séries temporais ${ }^{10}$. Nessas regressões é possível estabelecer uma relação de longo prazo entre ambas as variáveis, conforme esperado pela teoria. A única exceção parece ser o caso do Japão. As relações de longo prazo válidas apresentam coeficientes de longo prazo variam entre 0,22 e 0,42 para esse setor. Após a inserção das demais variáveis e estimação dos modelos em painel, espera-se que esse padrão de resultado seja replicado para toda amostra. Antes porém, é interessante testar as hipóteses de existência de raiz unitária nas séries e existência de cointegração entre as mesmas. São apresentados na Tabela 3 testes de raiz unitária em painel de $1 a$ e $2 a$ geração ${ }^{11}$. Como é possível observar em ambos os testes ocorre a rejeição da hipótese nula de existência de raiz unitária para as séries de relativo de preços e de produção doméstica. Entretanto, esses testes de raiz unitária em painel, mesmo o de Pesaran (2007), não permitem a cointegração entre as unidades do painel ${ }^{12}$. Segundo Barbieri (2009) esse tipo de teste tende a rejeitar a hipótese de não estacionariedade caso séries cointegradas estejam presentes no painel, algo bastante provável quando se consideram séries de produção, ou mesmo de séries preços relativos. Quando conduzidos testes DF-GLS de raiz unitária para as séries individualmente não foi possível rejeitar a hipótese nula para a maioria das séries analisadas ${ }^{13}$. Dadas essas evidências ambíguas para todo o conjunto das séries utilizadas no estudo assumimos a presença de raiz unitária nas séries e conduzimos um teste de cointegração.

Para isso, realizamos o teste de cointegração em painel proposto por Westerlund (2007). O teste parte da estimação de um modelo de correção de erros em painel, não impondo restrições sobre os coeficientes, e testa para a significância do termo de correção de erros, sob hipótese nula de ausência de

\footnotetext{
${ }^{8} \mathrm{O}$ índice de rentabilidade das exportações é calculado a partir da razão entre o índice de preço das exportações, cotado em moeda nacional, e o índice de custo das exportações. A metodologia de cálculo desse índice é apresentada no Texto para Discussão N 130 da FUNCEX.

${ }^{9}$ Esse setor foi escolhido pois há dados para todos os países da amostra.

${ }^{10}$ Os modelos $\operatorname{ARDL}(p, q)$ podem ser utilizados para detecção de correlação entre séries temporais sem incorrer no risco de estimação de regressões espúrias. Para mais informações ver Hamilton (1994).

${ }^{11}$ Os testes de $1^{a}$ geração não consideram a possibilidade de dependência em cross-section no painel, enquando que os testes de $2^{a}$ geração admitem essa possibilidade. O teste de Pesaran (2007) faz isso por meio da estimação teste Dickey-Fulller Aumentado Tranversalmente (Crosssectionally Augmented (DF-CADF), que consiste de regressões em que são incluídas médias em cross-section dos níveis defasados e das primeiras diferenças defasadas das séries.

${ }^{12}$ Os testes utilizados aqui foram selecionados de acordo com a disponibilidade do software Stata.

${ }^{13}$ Os resultados desses testes individuais são omitidos aqui por questões de espaço.
} 
Tabela 1: Estatísticas Descritivas em Painel

\begin{tabular}{lccccccr}
\hline Variável & Média & D. Padrão & Mínimo & Máximo & Obs. & & \\
\hline Preço Relativo & Total & 4,707 & 0,2640 & 3,460 & 5,756 & $N=6440$ \\
& Entre Grupos & & 0,1080 & 4,381 & 5,065 & $n=$ & 115 \\
& Intra Grupos & & 0,2410 & 3,551 & 5,795 & $T=$ & 56 \\
\multirow{2}{*}{ Taxa Real de Câmbio } & Total & 4,717 & 0,3090 & 4,156 & 5,471 & $N=$ & 336 \\
& Entre Grupos & & 0,0600 & 4,637 & 4,790 & $n=$ & 6 \\
& Intra Grupos & & 0,3040 & 4,198 & 5,457 & $T=$ & 56 \\
Taxa Nominal de Câmbio & Total & 4,638 & 0,2990 & 4,003 & 5,934 & $N=$ & 324 \\
& Entre Grupos & & 0,0780 & 4,552 & 4,758 & $n=$ & 6 \\
& Intra Grupos & & 0,2900 & 3,883 & 5,815 & $T=$ & 54 \\
Produto Externo & Total & 4,551 & 0,2150 & 3,807 & 5,151 & $N=$ & 336 \\
& Entre Grupos & & 0,0270 & 4,504 & 4,584 & $n=$ & 6 \\
Produção Doméstica & Intra Grupos & & 0,2130 & 3,794 & 5,139 & $T=$ & 56 \\
& Total & 4,561 & 0,1910 & 3,621 & 5,368 & $N=1456$ \\
& Entre Grupos & & 0,0068 & 4,354 & 4,648 & $n=$ & 26 \\
Custo & Intra Grupos & & 0,1790 & 3,650 & 5,281 & $T=$ & 56 \\
& Total & 4,628 & 0,4600 & 3,185 & 5,718 & $N=1456$ \\
& Entre Grupos & & 0,0820 & 4,476 & 4,840 & $n=$ & 26 \\
& Intra Grupos & & 0,4530 & 3,327 & 5,702 & $T=$ & 56 \\
\hline
\end{tabular}

Fonte: Elaboração Própria. 
Figura 1: Taxa Real de Câmbio contra o Preço Relativo no Setor de Siderurgia por País

Argentina

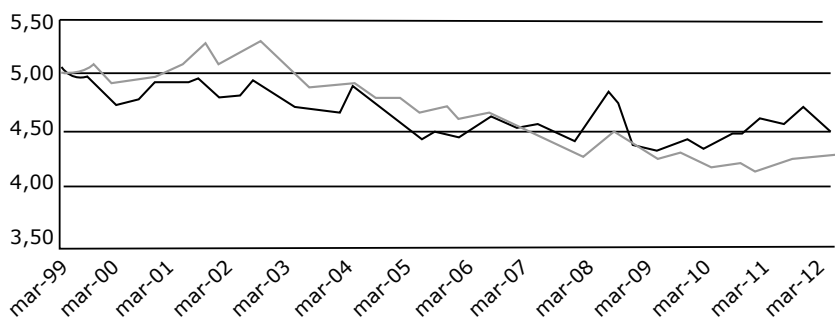

—_ Preço relativo

\section{China}

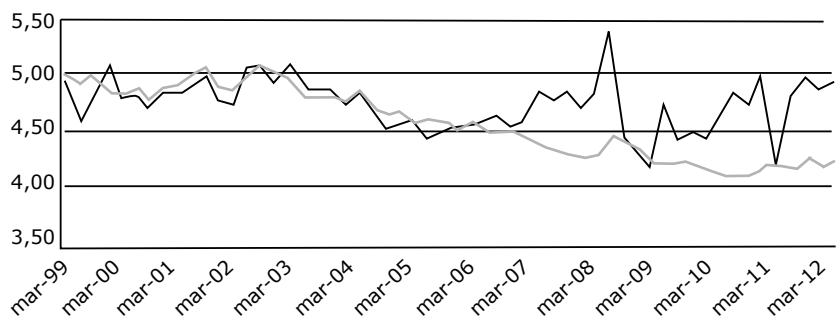

_ Preço relativo

Japão

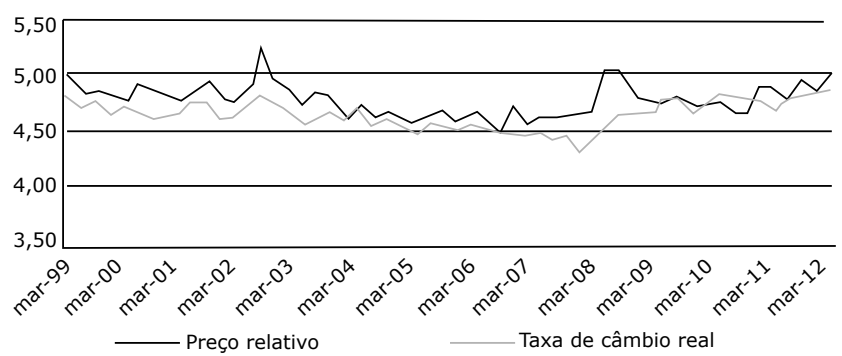

Fonte: Elaboração Própria.
Chile

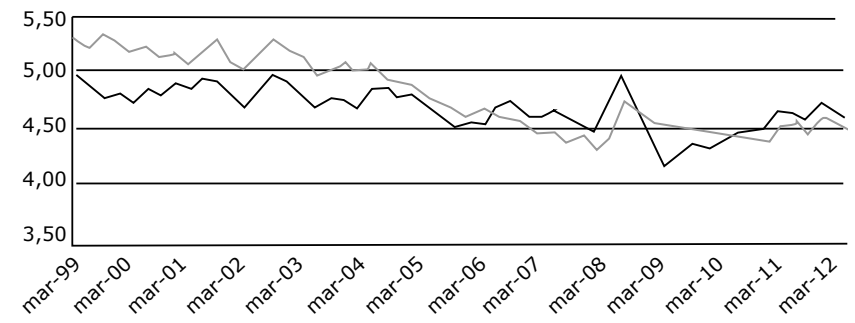

—_ Preço relativo

Estados Unidos

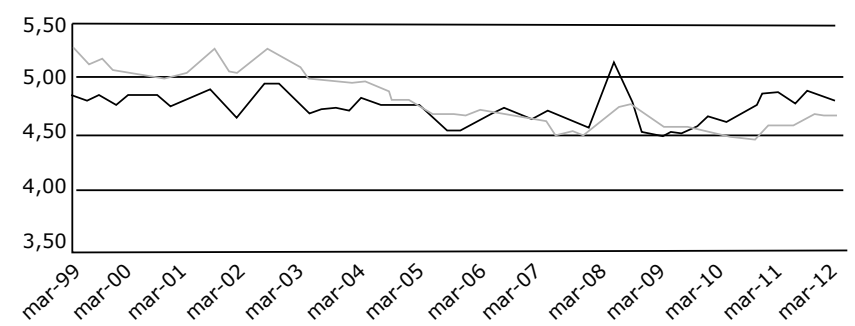

_ Preço relativo

México

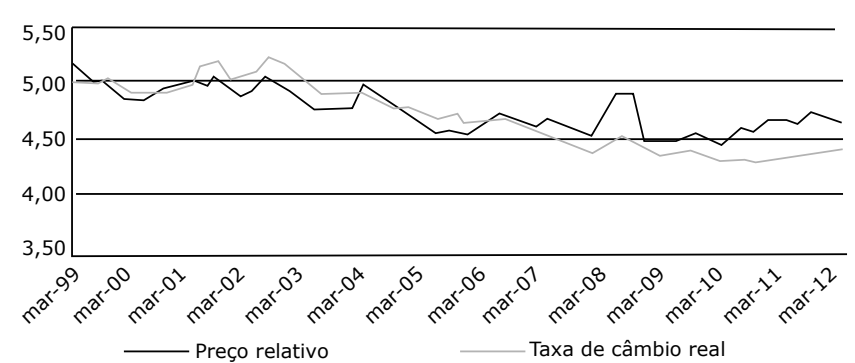


Tabela 2: Modelo ARDL(1,1): Relativo de Preços versus Taxa Real de Câmbio - Siderurgia

\begin{tabular}{|c|c|c|c|c|c|c|}
\hline Variáveis & Argentina & Chile & China & Estados Unidos & Japão & México \\
\hline$R_{i} t$ & $\begin{array}{l}1,020^{* * *} \\
(0,176)\end{array}$ & $\begin{array}{l}0,919^{* * *} \\
(0,133)\end{array}$ & $\begin{array}{l}1,078^{* * *} \\
(0,334)\end{array}$ & $\begin{array}{l}1,173^{* * *} \\
(0,140)\end{array}$ & $\begin{array}{l}0,685^{* * *} \\
(0,184)\end{array}$ & $\begin{array}{l}0,761^{* * *} \\
(0,157)\end{array}$ \\
\hline$R_{i} t-1$ & $\begin{array}{c}-0,879^{* * *} \\
(0,182)\end{array}$ & $\begin{array}{c}-0,785^{* * *} \\
(0,138)\end{array}$ & $\begin{array}{c}-0,915^{* * *} \\
(0,331)\end{array}$ & $\begin{array}{c}-1,099^{* * *} \\
(0,139)\end{array}$ & $\begin{array}{c}-0,708^{* * *} \\
(0,185)\end{array}$ & $\begin{array}{c}-0,687^{* * * *} \\
(0,155)\end{array}$ \\
\hline$X_{i} t-1$ & $\begin{array}{l}0,672^{* * *} \\
(0,086)\end{array}$ & $\begin{array}{c}0,693^{* * *} \\
0,091\end{array}$ & $\begin{array}{l}0,255^{*} \\
(0,129)\end{array}$ & $\begin{array}{l}0,655^{* * *} \\
(0,079)\end{array}$ & $\begin{array}{l}0,936^{* * *} \\
(0,062)\end{array}$ & $\begin{array}{l}0,700^{* * * *} \\
(0,091)\end{array}$ \\
\hline Constante & $\begin{array}{l}0,905^{* * *} \\
(0,247)\end{array}$ & $\begin{array}{l}0,794^{* * *} \\
(0,271)\end{array}$ & $\begin{array}{l}2,796^{* * * *} \\
(0,566)\end{array}$ & $\begin{array}{l}1,279^{* * *} \\
(0,326)\end{array}$ & $\begin{array}{l}0,431 \\
(0,440)\end{array}$ & $\begin{array}{l}1,096^{* * * *} \\
(0,358)\end{array}$ \\
\hline $\begin{array}{l}\text { Relação de } \\
\text { Longo Prazo }\end{array}$ & 0,430 & 0,437 & 0,219 & 0,217 & $-0,372$ & 0,247 \\
\hline Obs. & 55 & 55 & 55 & 55 & 55 & 55 \\
\hline
\end{tabular}

Erro padrão entre parênteses.

* significante a $10 \%$; ${ }^{* *}$ significante a $5 \%$; ${ }^{* * *}$ significante a $1 \%$.

Fonte: Elaboração Própria.

cointegração ${ }^{14}$. Os resultados dos testes de cointegração apresentados na Tabela 4 indicam a rejeição à hipótese de ausência de cointegração em painel. Dado isso, serão apresentadas na seção seguinte os resultados dos modelos de correção de erro em painel.

\section{Resultados}

Com base nos resultados, testes de cointegração, foram calculados modelos de correção de erros em painel. Ao realizar a estimação MG (os coeficientes são calculados a partir da média dos coeficientes das regressões de cada série), foi observado que em 22 séries o coeficiente associado à variável de taxa real de câmbio no longo prazo apresentou sinal negativo (inconsistentes segundo a teoria), sendo retiradas da amostra ${ }^{15}$. Com a exclusão dessas séries a amostra ficou com 5208 observações, a partir de 93 unidades de cross-section e 56 períodos.

Na Tabela 5 podemos observar os resultados das estimações dos modelos de correção de erros. Iniciando pela relação de longo prazo, observamos que as elasticidades estimadas pelos estimadores Pooled foram inferiores às estima-

\footnotetext{
${ }^{14}$ Definindo $\alpha_{i}$ a estimativa da velocidade de correção de erros para o equilíbrio de longo prazo, e parâmetros individuais de inclinação específica, as estatísticas $G_{a}$ e $G_{t}$ testam com hipótese nula que a $i=0$ para todo $i$, contra a hipótese nula de que a $i<0$ para algum $i$. A rejeição da hipótese nula indica que pelo menos alguma das séries cointegra. As estatísticas $P_{a}$ e $P_{t}$ analisam a existência de cointegração para o painel inteiro, assim a hipótese nula é que a $i=0$ para todo $i$, contra a hipótese nula de que a $i<0$ para todo $i$. A rejeição da hipótese nula fornece evidências de cointegração para o painel como um todo. Segundo Westerlund (2007), os testes são capazes de acomodar dinâmicas individuais de curto prazo específicas, incluindo termos de erro correlacionados em série, regressores não estritamente exógenos, termos específicos de intercepto e tendências individuais. Utiliza técnica de bootstrap para lidar com o problema de dependência em cross-section.

${ }^{15}$ As séries que apresentaram inconsistências foram: agropecuária para a China; extrativa mineral para a China e Japão; siderurgia para o Japão; metalurgia não ferrosos para o Japão; equipamentos eletrônicos para o México; veículos automotores para o Chile; peças e outros veículos para o Chile; madeira e mobiliário para o Japão; celulose, papel e gráfica para os Estados Unidos e Japão; farmacêutica e perfumaria para o Chile; calçados para o Chile; Café para a Argentina, Chile e Estados Unidos; beneficiamento de produtos vegetais para o Chile; abate de animais para a Argentina e Japão; óleos vegetais para a China e Japão; e outros produtos alimentares para a Argentina.
} 
Tabela 3: Testes de Raiz Unitária - Maddala \& Wu (1999)

\begin{tabular}{lcccc}
\hline Variáveis & $\begin{array}{c}\text { Sem Tendência } \\
\text { Chi-quadrado }\end{array}$ & $\begin{array}{c}\text { Com Tendência } \\
\text { Chi-quadrado }\end{array}$ & $\begin{array}{c}\text { Sem Tendência } \\
\mathbf{Z}_{\mathbf{t}}-\mathbf{b a r}\end{array}$ & $\begin{array}{c}\text { Com Tendência } \\
\mathbf{Z}_{\mathbf{t}}-\mathbf{b a r}\end{array}$ \\
\hline Preço Relativo & $679,432^{* * *}$ & $626,385^{* * *}$ & $-16,832^{* * *}$ & $-19,567^{* * *}$ \\
Taxa Real de Câmbio & 7,167 & 8,783 & $-1,074$ & $-0,249$ \\
Taxa Nominal de Câmbio & 9,105 & 4,294 & 11,688 & 11,535 \\
Renda do País Importador & 6,051 & 3,355 & 6,807 & 2,376 \\
Produção & $135,210^{* * *}$ & $261,786^{* * *}$ & $-7,379^{* * *}$ & $-9,879^{* * *}$ \\
Custo & 31,830 & 23,995 & $-1,165$ & $-5,080^{* * *}$ \\
\hline * significante a 10\%; ${ }^{* *}$ significante a 5\%;*** significante a 1\%.
\end{tabular}

* significante a $10 \% ;{ }^{* *}$ significante a $5 \%$; ${ }^{* * *}$ significante a $1 \%$.

Fonte: Elaboração Própria. 
Tabela 4: Teste de Cointegração de Westerlund (2007)

\begin{tabular}{lrrrrrr}
\hline \multirow{2}{*}{ Estatística } & \multicolumn{3}{c}{ Com Constante } & \multicolumn{2}{c}{ Com Constante e Tendência } \\
& \multicolumn{1}{c}{ Valor } & Z-valor & p-valor & \multicolumn{1}{c}{ Valor } & Z-valor & p-valor \\
\hline$G_{t}$ & $-4,119$ & $-18,791$ & 0,000 & $-4,299$ & $-16,968$ & 0,000 \\
$G_{a}$ & $-18,679$ & $-8,010$ & 0,000 & $-19,880$ & $-3,120$ & 0,001 \\
$P_{t}$ & 45,475 & $-20,711$ & 0,000 & $-47,217$ & $-19,054$ & 0,000 \\
$P_{a}$ & $-19,194$ & $-13,986$ & 0,000 & $-20,789$ & $-8,594$ & 0,000 \\
\hline
\end{tabular}

Fonte: Elaboração Própria.

tivas produzidas pelos estimadores MG. Os coeficientes associados à variável de taxa real de câmbio no longo prazo, que representam a elasticidade de precificação ao mercado, são positivos e estatisticamente significantes. Para os estimadores PMG e MG os coeficientes estimados são iguais a 0,411 e 0,705, respectivamente. A partir da realização de teste de Hausman, comparando as estimativas dos vetores de parâmetros de longo prazo dos estimadores PMG e $M G$, é rejeitada a hipótese nula de ausência de diferença entre os vetores, demonstrando a inconsistência do estimador $\mathrm{PMG}^{16}$.

Os coeficientes estimados segundo os estimadores DOLS e FMOLS situamse no intervalo entre 0,554 e 0,793. Dessa forma, podemos concluir que a elasticidade de precificação ao mercado deve se situar entre 0,55 a 0,8, sendo que considerando apenas as estimativas produzidas pelos estimadores MG situam-se no intervalo de 0,7 a 0,8 , indicando uma forte discriminação entre os mercados. Isto é, uma estimativa para o coeficiente de precificação próxima de 1 deve indicar que os preços em moeda estrangeira das exportações, e/ou os preços em moeda doméstica dos produtos comercializados no mercado doméstico, apresentam um baixo grau de repasse cambial no longo prazo, o que deve implicar em um distanciamento dos preços externo e doméstico quando cotados em uma mesma moeda.

Para as demais variáveis, no longo prazo verificamos o efeito positivo da renda externa sobre o relativo de preços, com elasticidades entre 0,38 e 0,66. Para a variável de custos, também com estimativas estatisticamente significativas, os coeficientes situaram-se entre 0,11 e 0,30, enquanto que para a variável de produção predominou as estimativas de elasticidades estatisticamente significativas, com coeficientes negativos entre $-0,11$ e $-0,40$. Essas estimativas estão em acordo com as predições teóricas do modelo.

A confirmação da validade da relação de longo prazo também é fornecida pela significância estatística dos coeficientes associados aos termos de correção de erros nos modelos. Em todos os modelos estimados, independentemente do estimador utilizado, os coeficientes apresentaram sinais negativos e são estatisticamente significante em um nível de significância de $1 \%$, com valores entre $-0,16$ e $-0,45$. A grande diferença se encontra no coeficiente estimado pelo método PMG, igual a $-0,451$. Nos demais modelos os coeficientes têm valor médio igual $-0,178$.

Para as estimativas da elasticidade de precificação ao mercado no curto prazo observamos dois tipos de resultados. Nos modelos em que o termo de correção de erro foi inserido posteriormente à estimação do vetor de cointegração (estimados pelos métodos DOLS e FMOLS), os coeficientes situam-se no intervalo entre 0,22 e 0,24. Ou seja, uma discriminação bastante menor entre o

\footnotetext{
${ }^{16}$ A estatística chi-quadrado com 4 graus de liberdade foi igual a 38,62, rejeitando a hipótese nula em um nível de significância de $1 \%$.
} 
Tabela 5: Modelos de Correção de Erros para Relativo de Preços

\begin{tabular}{|c|c|c|c|c|c|c|}
\hline Variáveis & PMG & MG & $\begin{array}{l}\text { DOLS } \\
\text { Pooled }\end{array}$ & $\begin{array}{c}\text { DOLS } \\
\text { Grouped }\end{array}$ & $\begin{array}{c}\text { FMOLS } \\
\text { Pooled }\end{array}$ & $\begin{array}{l}\text { FMOLS } \\
\text { Grouped }\end{array}$ \\
\hline \multicolumn{7}{|l|}{ Longo Prazo } \\
\hline Taxa Real de Ca & $\begin{array}{l}0,411^{* * *} \\
(0,028)\end{array}$ & $\begin{array}{c}0,705^{* * *} \\
0,069\end{array}$ & $\begin{array}{l}0,554^{* * * *} \\
(0,027)\end{array}$ & $\begin{array}{l}0,797^{* * *} \\
(0,040)\end{array}$ & $\begin{array}{c}0,616^{* * * *} \\
0,024\end{array}$ & $\begin{array}{c}0,673^{* * *} \\
0,022\end{array}$ \\
\hline Renda & $\begin{array}{l}0,224^{* * *} \\
(0,040)\end{array}$ & $\begin{array}{l}0,484^{* * *} \\
(0,179)\end{array}$ & $\begin{array}{l}0,256^{* * * *} \\
(0,035)\end{array}$ & $\begin{array}{l}0,746^{* * *} \\
(0,068)\end{array}$ & $\begin{array}{l}0,283^{* * *} \\
(0,032)\end{array}$ & $\begin{array}{l}0,470^{* * *} \\
(0,040)\end{array}$ \\
\hline Produção & $\begin{array}{l}0,107^{* * *} \\
(0,026)\end{array}$ & $\begin{array}{r}-0,250 \\
(0,170)\end{array}$ & $\begin{array}{c}-0,119^{* * *} \\
(0,029)\end{array}$ & $\begin{array}{c}-0,446^{* * *} \\
(0,073)\end{array}$ & $\begin{array}{c}-0,114^{* * *} \\
(0,027)\end{array}$ & $\begin{array}{c}-0,400^{* * * *} \\
(0,036)\end{array}$ \\
\hline Custo & $\begin{array}{l}0,119^{* * *} \\
(0,019)\end{array}$ & $\begin{array}{l}0,298^{* * *} \\
(0,077)\end{array}$ & $\begin{array}{l}0,091^{\text {****}} \\
(0,018)\end{array}$ & $\begin{array}{l}0,358^{* * *} \\
(0,034)\end{array}$ & $\begin{array}{l}0,115^{* * *} \\
(0,017)\end{array}$ & $\begin{array}{l}0,215^{* * * *} \\
(0,020)\end{array}$ \\
\hline \multicolumn{7}{|l|}{ Curto Prazo } \\
\hline Taxa Real de & $\begin{array}{l}0,140^{* * *} \\
(0,042)\end{array}$ & $\begin{array}{l}0,008 \\
(0,037)\end{array}$ & $\begin{array}{l}0,225^{* * *} \\
(0,027)\end{array}$ & $\begin{array}{l}0,234^{* * *} \\
(0,027)\end{array}$ & $\begin{array}{l}0,226^{* * *} \\
(0,027)\end{array}$ & $\begin{array}{l}0,240^{* * *} \\
(0,027)\end{array}$ \\
\hline Renda & $\begin{array}{l}0,664^{* * * *} \\
(0,104)\end{array}$ & $\begin{array}{l}0,505^{* * *} \\
(0,099)\end{array}$ & $\begin{array}{l}0,442^{\text {**** }} \\
(0,046)\end{array}$ & $\begin{array}{l}0,380^{* * *} \\
(0,046)\end{array}$ & $\begin{array}{l}0,437^{* * *} \\
(0,046)\end{array}$ & $\begin{array}{l}0,414^{* * *} \\
(0,046)\end{array}$ \\
\hline Pro & $\begin{array}{c}-0,008 \\
(0,026)\end{array}$ & $\begin{array}{l}0,038 \\
(0,028)\end{array}$ & $\begin{array}{c}-0,021 \\
(0,018)\end{array}$ & $\begin{array}{c}0,013 \\
(0,018)\end{array}$ & $\begin{array}{r}-0,022 \\
(0,018)\end{array}$ & $\begin{array}{l}0,005 \\
(0,018)\end{array}$ \\
\hline Custo & $\begin{array}{r}-0,015 \\
(0,056)\end{array}$ & $\begin{array}{r}-0,076 \\
(0,048)\end{array}$ & $\begin{array}{c}-0,056^{* * *} \\
(0,021)\end{array}$ & $\begin{array}{c}-0,066^{* * * *} \\
(0,021)\end{array}$ & $\begin{array}{c}-0,053^{* *} \\
(0,021)\end{array}$ & $\begin{array}{c}-0,054^{* * * *} \\
(0,021)\end{array}$ \\
\hline Taxa Nominal de Câmbio & $\begin{array}{c}0,009 \\
(0,025)\end{array}$ & $\begin{array}{r}-0,007 \\
(0,022)\end{array}$ & $\begin{array}{l}0,037^{* * *} \\
(0,015)\end{array}$ & $\begin{array}{l}0,059^{* * * *} \\
(0,015)\end{array}$ & $\begin{array}{l}0,040^{* * * *} \\
(0,015)\end{array}$ & $\begin{array}{l}0,050^{* * *} \\
(0,015)\end{array}$ \\
\hline Constante & $\begin{array}{l}0,154^{* * *} \\
(0,011)\end{array}$ & $\begin{array}{r}-0,745 \\
(0,516)\end{array}$ & $\begin{array}{l}0,177^{* * * *} \\
(0,008)\end{array}$ & $\begin{array}{c}-0,320^{* * * *} \\
(0,015)\end{array}$ & $\begin{array}{l}0,080^{* * *} \\
(0,004)\end{array}$ & $\begin{array}{l}0,029^{* * * *} \\
(0,002)\end{array}$ \\
\hline ECM & $\begin{array}{c}-0,234^{* * *} \\
(0,016)\end{array}$ & $\begin{array}{c}-0,451^{* * *} \\
(0,022)\end{array}$ & $\begin{array}{c}-0,175^{* * *} \\
(0,007)\end{array}$ & $\begin{array}{c}-0,151^{* * *} \\
(0,007)\end{array}$ & $\begin{array}{c}-0,174^{* * *} \\
(0,007)\end{array}$ & $\begin{array}{c}-0,160^{* * * *} \\
(0,007)\end{array}$ \\
\hline
\end{tabular}

Erro padrão entre parênteses.

${ }^{*}$ significante a $10 \%$; ${ }^{* *}$ significante a $5 \%$; ${ }^{* * *}$ significante a $1 \%$.

Fonte: Elaboração Própria.

mercado externo e doméstico no espaço de um trimestre. No entanto, quando comparados os coeficientes dos modelos estimados pelos métodos PMG e MG, observamos uma divergência quanto ao nível de significâncias dos coeficientes, sendo que pelo estimador MG o coeficiente de curto prazo não é estatisticamente significante. Obviamente, a diferença observada no valor estimado e na significância estatística do coeficiente estimado pelo método MG deve-se à suposição de heterogeneidade dos coeficientes tanto no longo, como no curto prazo. Já nos modelos em que realizada uma estimativa em dois estágios, em que no primeiro estágio é estimada a relação de cointegração, os coeficientes de curto prazo são estimados sob a suposição de homogeneidade no curto prazo, o que leva a um valor ligeiramente superior àquele estimado pelo método PMG.

De modo interessante, observamos que a pressão da renda externa sobre o relativo de preços é bastante superior àquela exercida pela taxa de câmbio no curto prazo, com coeficientes estimados que variam entre 0,38 e 0,66 , sendo este último estimado pelo método PMG. Sendo assim, variações da renda externa no curto prazo são importantes para determinar a discriminação de preços entre os mercados de variações cambiais. Já os coeficientes associados à variável de produção no curto prazo não se mostraram estatisticamente significativos, enquanto que os coeficientes associados à variável de custo foram em sua maior parte estatisticamente significativos (com exceção da estimação do coeficiente dos custos de curto prazo no PMG e no MG), mas negativos no curto prazo, com elasticidades em torno de $-0,05$. A variável representativa da surpresa cambial apresentou coeficientes estatisticamente significativos em um nível de significância de 5\%, com um valor médio de 0,05 , segundo as estimativas fornecidas pelos métodos DOLS e FMOLS. Ou seja, uma elasti- 
cidade bastante baixa, indica que além de transitória, essa variável tem baixo impacto sobre a discriminação de preços entre os mercados externo e doméstico.

O grau de precificação ao mercado pode estar relacionado ao tipo de produto que é transacionado em cada mercado, na medida em que as categorias de produtos podem estar associadas a diferentes padrões de demanda. Nesse sentido, realizamos estimações semelhantes dos modelos de correção de erro discriminados segundo as categorias de uso dos produtos (Bens de Capital, Bens Intermediários, Bens de Consumo Duráveis e Bens de Consumo não Duráveis) a fim de captar possíveis diferenciações no comportamento de formação de preços dos setores industriais no mercado externo.

Os resultados apresentados na Tabela 6 demonstram que os setores segundo as categorias de uso possuem graus de precificação ao mercado distintos tanto no curto, como no longo prazo. Observamos também uma maior divergência de estimativas de acordo com o estimador utilizado, não apenas em termos de magnitude dos coeficientes, como também em termos de significância estatística. Na maioria dos casos, os estimadores, DOLS e FMOLS apresentaram coeficientes estatisticamente significantes em um nível de significância de $1 \%$ e valores médios mais elevados que os estimadores MG e PMG. Na comparação entre os estimadores PMG e MG observamos também uma estimativa inferior para os coeficientes estimados por PMG, com exceção dos setores produtores de bens de consumo não duráveis, denotando provável inconsistência nessas estimativas.

As maiores elasticidades no longo prazo foram obtidas para os setores produtores de bens de capital, com estimativas entre 0,67 e 1,0, indicando um alto grau de precificação ao mercado e um baixo grau de repasse cambial aos preços externos. No extremo oposto, estão os setores produtores de bens de consumo duráveis, com graus de precificação ao mercado que vão de zero a 0,56 . Exibem estimativas similares e próximas à média dos resultados agregados aos setores produtores de bens intermediários e de consumo de bens não duráveis. Observamos também que as respostas no curto prazo são nulas nos setores produtores de bens de capital e consumo não duráveis, enquanto que nos setores de bens intermediários e bens de consumo duráveis as elasticidades de curto prazo se aproximam da média agregada para a maioria das estimativas, indicando repasse cambial incompleto aos preços externos. A liderança brasileira nas exportações de bens intermediários deve estar relacionada à maior capacidade de fixação de preços por parte das firmas brasileiras e, portanto, um menor grau de precificação à mercado. O maior grau de diferenciação dos produtos na categoria de bens de consumo duráveis também pode explicar o menor grau de precificação à mercado. $\mathrm{O}$ inverso deve ocorrer para o caso de bens de consumo não duráveis, enquanto que o menor grau de sofisticação tecnológica dos bens de capital exportados pelo Brasil deve fazer com que os mesmos fiquem mais expostos à pressão competitiva internacional.

\subsection{Teste para assimetria de resposta no curto prazo}

A princípio o modelo de Marston (1990) não prevê repasses assimétricos da taxa de câmbio. No entanto, conforme mencionado por Byrne et al. (2013) a existência de um markup sobre o custo marginal implica que a firma tem poder de mercado para manipular os preços a fim de estabilizar seus preços 
de exportação. Para Froot \& Klemperer (1989) o efeito assimétrico se justificaria em momentos de variações da taxa real de câmbio percebidas como temporárias, que seriam absorvidas por variações na margem de lucro bruta. À medida em que essas variações cambiais fossem percebidas como permanentes, a resposta dos preços dos exportadores operando no mercado externo seriam mais intensas considerando que tais efeitos prevaleceriam sobre os custos. Essa predição seria justificada pelo argumento de que firmas fazem face a um trade-off entre lucros correntes e futuros em razão da lealdade do consumidor ser considerada uma forma de custo irreversível e requerer descontos nos preços dos produtos.

Tabela 6: Elasticidades-Preço da Taxa Real de Câmbio por Categorias de Uso

\begin{tabular}{|c|c|c|c|c|c|c|}
\hline & PMG & MG & $\begin{array}{l}\text { DOLS } \\
\text { Pooled }\end{array}$ & $\begin{array}{c}\text { DOLS } \\
\text { Grouped }\end{array}$ & $\begin{array}{c}\text { FMOLS } \\
\text { Pooled }\end{array}$ & $\begin{array}{l}\text { FMOLS } \\
\text { Grouped }\end{array}$ \\
\hline \multicolumn{7}{|l|}{ Longo Prazo } \\
\hline Capital & $\begin{array}{l}0,364^{* * *} \\
(0,070)\end{array}$ & $\begin{array}{l}0,712^{* * *} \\
(0,178)\end{array}$ & $\begin{array}{l}0,669^{* * * *} \\
(0,048)\end{array}$ & $\begin{array}{l}0,942^{* * *} \\
(0,102)\end{array}$ & $\begin{array}{l}0,806^{* * *} \\
(0,049)\end{array}$ & $\begin{array}{l}1,045^{* * *} \\
(0,042)\end{array}$ \\
\hline Intermediários & $\begin{array}{l}0,361^{* * *} \\
(0,038)\end{array}$ & $\begin{array}{l}0,325^{* * *} \\
(0,171)\end{array}$ & $\begin{array}{l}0,456^{* * *} \\
(0,035)\end{array}$ & $\begin{array}{l}0,607^{* * *} \\
(0,037)\end{array}$ & $\begin{array}{l}0,498^{* * * *} \\
(0,039)\end{array}$ & $\begin{array}{l}0,703^{\text {*** }} \\
(0,023)\end{array}$ \\
\hline Consumo Não Duráveis & $\begin{array}{l}0,784^{* * *} \\
(0,071)\end{array}$ & $\begin{array}{l}0,654^{* * *} \\
(0,194)\end{array}$ & $\begin{array}{l}0,570^{* * * *} \\
(0,082)\end{array}$ & $\begin{array}{l}0,779^{* * * *} \\
(0,101)\end{array}$ & $\begin{array}{l}0,670^{* * *} \\
(0,085)\end{array}$ & $\begin{array}{l}0,810^{* * * *} \\
(0,048)\end{array}$ \\
\hline Consumo Duráveis & $\begin{array}{c}0,079 \\
(0,055)\end{array}$ & $\begin{array}{l}0,175 \\
(0,261)\end{array}$ & $\begin{array}{l}0,241^{* * * *} \\
(0,052)\end{array}$ & $\begin{array}{l}0,322^{* * * *} \\
(0,080)\end{array}$ & $\begin{array}{l}0,308^{* * * *} \\
(0,055)\end{array}$ & $\begin{array}{l}0,557^{* * *} \\
(0,045)\end{array}$ \\
\hline \multicolumn{7}{|l|}{ Curto Prazo } \\
\hline Capital & $\begin{array}{l}0,007 \\
(0,069)\end{array}$ & $\begin{array}{r}-0,045 \\
(0,075)\end{array}$ & $\begin{array}{l}0,014 \\
(0,053)\end{array}$ & $\begin{array}{l}0,066 \\
(0,054)\end{array}$ & $\begin{array}{l}0,025 \\
(0,053)\end{array}$ & $\begin{array}{l}0,081 \\
(0,054)\end{array}$ \\
\hline Intermediários & $\begin{array}{l}0,135^{* *} \\
(0,059)\end{array}$ & $\begin{array}{l}0,020 \\
(0,054)\end{array}$ & $\begin{array}{l}0,252^{* * * *} \\
(0,032)\end{array}$ & $\begin{array}{l}0,247 \\
(0,032)\end{array}$ & $\begin{array}{l}0,253^{* * * *} \\
(0,032)\end{array}$ & $\begin{array}{l}0,243^{\text {***}} \\
(0,032)\end{array}$ \\
\hline Consumo Não Duráveis & $\begin{array}{c}0,005 \\
(0,085)\end{array}$ & $\begin{array}{r}-0,068 \\
(0,079)\end{array}$ & $\begin{array}{r}-0,038 \\
(0,091)\end{array}$ & $\begin{array}{l}0,008 \\
(0,091)\end{array}$ & $\begin{array}{r}-0,033 \\
(0,091)\end{array}$ & $\begin{array}{l}0,025 \\
(0,092)\end{array}$ \\
\hline Consumo Duráveis & $\begin{array}{c}0,058 \\
(0,082)\end{array}$ & $\begin{array}{r}-0,004 \\
(0,063)\end{array}$ & $\begin{array}{l}0,204^{* * *} \\
(0,053)\end{array}$ & $\begin{array}{l}0,205^{\text {****}} \\
(0,053)\end{array}$ & $\begin{array}{l}0,205^{* * *} \\
(0,053)\end{array}$ & $\begin{array}{l}0,192^{* * *} \\
(0,053)\end{array}$ \\
\hline
\end{tabular}

Nesse sentido, em um momento de apreciação da taxa de câmbio é possível que o exportador, a fim de evitar um aumento de preços em moeda estrangeira, possa reduzir os preços de exportação suavizando o comportamento de preços no mercado internacional. Por outro lado, em momentos de depreciação cambial, mesmo que temporárias, pode haver um incentivo à expansão de sua parcela de mercado que venham produzir efeitos histeréticos sobre a demanda no longo prazo. Sendo assim, verificada a relação de longo prazo entre o relativo de preços e a taxa real de câmbio, é possível admitir que no curto prazo possa existir assimetria na resposta do relativo de preços às variações da taxa de câmbio real em função de desalinhamentos temporários da taxa real de câmbio.

A fim de testar se a elasticidade de precificação ao mercado no curto prazo responde diferentemente a desvios temporários da taxa de câmbio real em momentos de sobreapreciação ou sobredepreciação, é conduzida a estimação do modelo em painel com parâmetros limiares em painel proposto por Hansen (1999), em que o efeito da variável limiar manifesta-se por meio da instabilidade da elasticidade de precificação ao mercado no curto prazo segundo o modelo de correção de erro derivado a partir do modelo $\operatorname{ARDL}(2,1,1,1)$. A 
Equação (5.1) apresenta a especificação não linear para o parâmetro de elasticidade de precificação ao mercado no curto prazo.

$$
\Delta x_{i t}=\left\{\begin{array}{l}
\alpha_{11} \Delta r_{i t}\left(\omega_{i t}\right)+\alpha_{2} \Delta z_{i t}+\alpha_{3} \Delta y_{i t}+\alpha_{4} \Delta c_{j t}+ \\
\alpha_{5}\left(\Delta s_{i t}-\Delta s_{i t-1}+\alpha_{6} e c m_{i j t}+\epsilon_{i j t}, \text { se } \omega_{i t} \leq \gamma_{1}\right. \\
\alpha_{12} \Delta r_{i t}\left(\omega_{i t}+\alpha_{2} \Delta z_{i t}+\alpha_{3} \Delta y_{i t}+\alpha_{4} \Delta c_{j t}+\right. \\
\alpha_{5}\left(\Delta s_{i t}-\Delta s_{i t-1}+\alpha_{6} e c m_{i j t}+\epsilon_{i j t}, \text { se } \gamma_{1}<\omega_{i t} \leq \gamma_{2}\right. \\
\vdots \\
\alpha_{1 k} \Delta r_{i t}\left(\omega_{i t}\right)+\alpha_{2} \Delta z_{i t}+\alpha_{3} \Delta y_{i t}+\alpha_{4} \Delta c_{j t}+ \\
\alpha_{5}\left(\Delta s_{i t}-\Delta s_{i t-1}+\alpha_{6} e c m_{i j t}, \text { se } \omega_{i t}>\gamma_{k-1}\right.
\end{array}\right.
$$

A quantidade de coeficientes de inclinação $\left(\alpha_{11}, \alpha_{12}, \ldots, \alpha_{1 k}\right)$ representada pelo índice $\mathrm{k}=1,2, \ldots, \mathrm{K}$; o tempo $\mathrm{t}=1,2, \ldots . \mathrm{T}$; os $\mathrm{i}=1,2$, . . . I I países; e $\mathrm{j}=1,2, \ldots$. J setores; $\omega_{i t}$ é a variável limiar (desalinhamento cambial) cujos valores definem o parâmetro limiar $\gamma_{k}$. Os parâmetros $\alpha_{1 k}$ associados à taxa real de câmbio $r_{i t}$ variam em função da variável limiar $\omega_{i t}$. O parâmetro limiar $\gamma_{k}$ divide as observações em regimes dependendo da variável limiar $\omega_{i t}$.

Para determinar se o efeito de limiar é estatisticamente significativo, testamos a hipótese nula de inexistência de efeito de limiar em 5.1 por meio da restrição linear $H_{0}: \alpha_{11}=\alpha_{12}$ (no caso de apenas dois regimes). As estimações das equações para $\Delta_{x i j t}$ é realizada com controle para efeitos fixos, sendo a estimativa do parâmetro limiar $\gamma$ dada por $\gamma=\operatorname{argmin} S_{1}(\gamma)$, em que $S_{1}$ é a soma dos quadrados dos resíduos concentrados da regressão de $\Delta_{x i j t}$.

Sob $H_{0}$ o parâmetro limiar $\gamma$ não é identificado, de modo que os testes clássicos têm distribuições não padrão. Hansen (1999) sugeriu a simulação à distribuição assintótica do teste da razão de verossimilhança por meio de bootstrap. Quando existe mais do que um regime, Hansen (1999) também mostrou que $\gamma$ é consistente para o verdadeiro valor de $\gamma$ e que a distribuição assintótica é não padrão. O número de coeficientes de limiares (e regimes) são determinados a partir de testes sequenciais de razão de verossimilhança $(\mathrm{LR})^{17}$.

Para representar esses desvios temporários foram calculadas três medidas de desalinhamento cambial para as taxas reais de câmbio dos seis países considerados. A primeira variável foi construída como o desvio entre a variável suavizada produzida pelo filtro de Hodrick-Prescott (desalinhamento HP) e a medida de taxa real de câmbio. A segunda medida foi obtida como resíduo de uma equação para a paridade de poder de compra relativa (PPC-1) e a terceira, bastante similar à segunda, é derivada a partir da reparemetrização de um modelo $\operatorname{ARDL}(1,1,1)$ na forma de modelo de correção de erros para taxa nominal de câmbio, em que as variáveis dependentes são os índices de preços ao atacado doméstico e estrangeiro (PPC-2).

As estatísticas descritivas referentes às medidas de desalinhamento cambial são apresentadas na Tabela 7. Conforme é possível observar nessa tabela

\footnotetext{
${ }^{17}$ Especificamente nas estimações que envolvem os métodos de Pesaran \& Smith (1995) e Pesaran et al. (1999) realizamos o procedimento de Hansen com o modelo em efeitos fixos e, posteriormente à definição dos valores limiares, implementamos as respectivas metodologias com a introdução de variáveis dummies interadas aos coeficientes de curto prazo.
} 
as medidas produzidas pelo filtro HP apresentam maior variabilidade, com um desvio padrão em média 8,7 vezes superior ao desvio da medida PPC-1 e 7,7 vezes superior ao desvio da medida PPC-2. Também é a medida que apresenta maior coeficiente de curtose médio (igual a 4,14 contra 3,62 para PPC-1 e 3,14 para PPC-2, respectivamente), indicando maior frequência de valores extremos também para esse tipo de variável. As medidas PPC-1 e PPC-2 apresentam estatísticas similares dado que foram geradas a partir de modelos econométricos semelhantes. Porém, a medida PPC-1 apresenta coeficientes de assimetria e curtose ligeiramente superiores ao da medida PPC-2. Para todas as medidas de desalinhamento os desvios da taxa real de câmbio da Argentina apresentaram maior variabilidade e assimetria.

Os resultados dos testes de linearidade e as estimativas de curto prazo da elasticidade do câmbio são apresentados na Tabela 8. Os testes LR indicam a rejeição da hipótese nula de linearidade, em um nível de significância de $1 \%$, contra a hipótese de dois regimes para todos os modelos que utilizaram como variável limiar a medida do desalinhamento HP e PPC-1. Para os modelos que foram testados com a variável limiar PPC-2 apenas aquele estimado por meio do estimador Pooled Mean Grouped foi capaz de rejeitar a mesma hipótese nula em nível de significância 1\%. Os testes para a existência de 3 regimes, contra a hipótese nula de 2 regimes, não permitiram rejeitar a hipótese nula para as variáveis limiares HP e PPC-1. No caso da variável PPC-2, inconsistentemente, os testes de linearidade rejeitaram a mesma hipótese nula em um nível de significância de $5 \%{ }^{18}$. A fim de manter a coerência na apresentação, descartamos esses resultados e apresentamos na Tabela 8 os resultados para modelos de correção de erros com dois regimes (apenas 1 parâmetro limiar), inclusive com as estimativas com a variável limiar de PPC- 2 .

Tabela 7: Estatísticas Descritivas: Medidas de Desalinhamento Cambial

\begin{tabular}{lccrrrrr}
\hline Variável & Estatística & Argentina & Chile & China & EUA & México & Japão \\
\hline HP & Média & 0,000 & 0,000 & 0,000 & 0,000 & 0,000 & 0,000 \\
& Desvio Padrão & 0,103 & 0,078 & 0,095 & 0,078 & 0,079 & 0,097 \\
& Assimetria & $-0,095$ & $-0,033$ & 0,702 & 0,635 & 1,060 & 0,519 \\
& Curtose & 6,774 & 3,886 & 3,103 & 3,125 & 4,135 & 3,657 \\
PPC-1 & Média & 0,000 & 0,000 & 0,000 & 0,000 & 0,000 & 0,000 \\
& Desvio Padrão & 0,012 & 0,010 & 0,010 & 0,010 & 0,009 & 0,014 \\
& Assimetria & 1,281 & 0,135 & $-0,109$ & $-0,137$ & 0,329 & 0,025 \\
& Curtose & 6,170 & 2,511 & 3,009 & 2,813 & 3,216 & 3,998 \\
PPC-2 & Média & 0,000 & 0,000 & 0,000 & 0,000 & 0,000 & 0,000 \\
& Desvio Padrão & 0,011 & 0,009 & 0,008 & 0,010 & 0,009 & 0,012 \\
& Assimetria & 1,047 & 0,128 & 0,062 & $-0,086$ & 0,367 & $-0,345$ \\
& Curtose & 5,313 & 2,528 & 2,387 & 2,490 & 3,255 & 2,866 \\
\hline
\end{tabular}

Fonte: Elaboração Própria.

Denominamos de primeiro regime (Regime 1) os valores do desvios inferiores ao valor limiar e segundo regime (Regime 2) os valores dos desvios superiores aos valores limiares. Como é possível observar também na Tabela 8 os valores limiares estão todos bastante próximos de zero, indicando que

\footnotetext{
${ }^{18}$ Os resultados desses modelos indicaram padrão de assimetria semelhante. No entanto, o regime intermediário em alguns casos apresentaram coeficientes inconsistentes com a teoria e em outros casos iguais a zero estatisticamente.
} 
o primeiro regime é composto por movimentos de sobreapreciação cambial, enquanto que o segundo regime é composto por movimentos de sobredepreciação cambial.

Dois tipos de resultados, em termos de magnitude dos coeficientes, podem ser distinguidos. O primeiro para a variável de desalinhamento HP, em que os coeficientes para o primeiro regime não são significativos estatisticamente em um nível de significância de $10 \%$, com magnitudes estimadas próximas de zero, enquanto que a magnitude dos coeficientes estimados para o segundo regime são superiores às estimativas do modelo linear (média das estimativas igual a 0,33 contra 0,18 do modelo linear) com valores situados no intervalo entre 0,287 e 0,355 .

O segundo tipo de resultado é aquele proveniente das estimativas com a variável limiar PPC. Tanto no caso da variável limiar PPC-1, como para a variável PPC-2, os coeficientes para o primeiro regime são estatisticamente significativos com elasticidades estimadas entre 0,087 e 0,146 para coeficientes associados à variável limiar é PPC-1, e entre 0,079 e 0,169 no caso da variável limiar PPC-2. Isto é, para esse tipo de variável mesmo em períodos de apreciação existe uma resposta dos exportadores em termos de preços, permitindo uma elevação dos preços de exportação, porém em menor magnitude do que nos períodos de sobredepreciação. Os coeficientes estimados para o segundo regime situaram-se entre 0,443 e 0,532 quando a variável limiar é PPC-1 e 0,282 e 0,319 no caso da variável limiar PPC-2. Ou seja, as estimativas de elasticidade de precificação ao mercado em momentos de sobredepreciação com a variável limiar PPC-1 foram as mais elevadas, revelando uma resposta mais acentuada em termos de declínio dos preços dos exportadores.

Assim sendo, de modo geral, as estimativas de modelos de correção não lineares para a elasticidade de precificação à mercado, utilizando variáveis limiares calculadas na forma de desalinhamentos cambiais, apontaram que os exportadores, ao menos no curto prazo fazem uso de uma política de preços que busca suavizar os aumentos de preços produzidos pelos movimentos de sobreapreciação cambial, repassando aos preços de exportação os impactos das desvalorizações cambiais, possivelmente, com a intenção de avançar em seus mercados externos.

\section{Conclusões}

Esse artigo avança na literatura de precificação aos mercados com uma implementação empírica do modelo de Marston (1990) com modelos de cointegração em painel e estimações de modelos de correção de erros lineares e não lineares a partir de dados para seis destinos das exportações brasileiras no período de 1999 a 2012. A utilização de diversos estimadores para a relação de cointegração permitiu comparar as estimativas de elasticidades de precificação ao mercado no longo prazo. As estimativas de longo prazo produzidas por estimadores Pooled situaram-se no intervalo de 0,41 a 0,61, enquanto que as estimativas produzidas pelos estimadores Mean Grouped se situaram no intervalo de 0,67 , a 0,79 . O valor mediano para a elasticidade de precificação a mercado foi de 0,64 e o valor médio de 0,62. Considerando esses valores médio e mediano relativamente elevados, porém inferiores a 1 , pode-se concluir que existe uma sensível discriminação de preços entre mercado interno e externo para os produtos manufaturados de exportações. 
Tabela 8: Modelos de Correção de Erros com Threshold

\begin{tabular}{|c|c|c|c|c|c|c|}
\hline & PMG & MG & $\begin{array}{l}\text { DOLS } \\
\text { Pooled }\end{array}$ & $\begin{array}{c}\text { DOLS } \\
\text { Grouped }\end{array}$ & $\begin{array}{c}\text { FMOLS } \\
\text { Pooled }\end{array}$ & $\begin{array}{l}\text { FMOLS } \\
\text { Grouped }\end{array}$ \\
\hline \multicolumn{7}{|l|}{ Desalinhamento HP } \\
\hline Valor Limiar & $-0,033$ & $-0,050$ & $-0,050$ & $-0,050$ & $-0,050$ & $-0,050$ \\
\hline Teste LR & 41,538 & 41,031 & 51,200 & 55,302 & 51,829 & 51,719 \\
\hline p-valor & 0,023 & 0,003 & 0,000 & 0,030 & 0,017 & 0,013 \\
\hline \multicolumn{7}{|l|}{ Coeficientes } \\
\hline Regime 1 & $\begin{array}{c}0,029 \\
(0,033)\end{array}$ & $\begin{array}{c}0,034 \\
(0,034)\end{array}$ & $\begin{array}{c}0,036 \\
(0,034)\end{array}$ & $\begin{array}{c}0,053 \\
(0,035)\end{array}$ & $\begin{array}{r}0,037 \\
(0,0034)\end{array}$ & $\begin{array}{c}0,057 \\
(0,034)\end{array}$ \\
\hline Regime 2 & $\begin{array}{c}0,287 \\
(0,035)\end{array}$ & $\begin{array}{c}0,297 \\
(0,034)\end{array}$ & $\begin{array}{c}0,328 \\
(0,034)\end{array}$ & $\begin{array}{c}0,355 \\
(0,034)\end{array}$ & $\begin{array}{c}0,331 \\
(0,034)\end{array}$ & $\begin{array}{c}0,355 \\
(0,034)\end{array}$ \\
\hline \multicolumn{7}{|l|}{ PPC Relativa 1} \\
\hline Valor Limiar & 0,036 & 0,038 & 0,038 & 0,038 & 0,038 & 0,038 \\
\hline Teste LR & 50,513 & 56,617 & 51,522 & 55,302 & 53,186 & 53,041 \\
\hline p-valor & 0,010 & 0,003 & 0,027 & 0,030 & 0,017 & 0,013 \\
\hline \multicolumn{7}{|l|}{ Coeficientes } \\
\hline Regime 1 & $\begin{array}{c}0,087 \\
(0,028)\end{array}$ & $\begin{array}{c}0,102 \\
(0,028)\end{array}$ & $\begin{array}{c}0,124 \\
(0,028)\end{array}$ & $\begin{array}{c}0,143 \\
(0,029)\end{array}$ & $\begin{array}{c}0,125 \\
(0,028)\end{array}$ & $\begin{array}{c}0,146 \\
(0,028)\end{array}$ \\
\hline Regime 2 & $\begin{array}{c}0,443 \\
(0,050)\end{array}$ & $\begin{array}{c}0,490 \\
(0,050)\end{array}$ & $\begin{array}{c}0,493 \\
(0,051)\end{array}$ & $\begin{array}{c}0,532 \\
(0,052)\end{array}$ & $\begin{array}{c}0,501 \\
(0,052)\end{array}$ & $\begin{array}{c}0,526 \\
(0,052)\end{array}$ \\
\hline \multicolumn{7}{|l|}{ PPC Relativa 2} \\
\hline Valor Limiar & 0,001 & 0,005 & 0,001 & 0,005 & 0,001 & 0,001 \\
\hline Teste LR & 23,768 & 15,297 & 16,244 & 11,288 & 15,348 & 11,663 \\
\hline p-valor & 0,020 & 0,160 & 0,110 & 0,510 & 0,133 & 0,513 \\
\hline \multicolumn{7}{|l|}{ Coeficientes } \\
\hline Regime 1 & $\begin{array}{c}0,079 \\
(0,031)\end{array}$ & $\begin{array}{c}0,122 \\
(0,029)\end{array}$ & $\begin{array}{c}0,126 \\
(0,030)\end{array}$ & $\begin{array}{c}0,169 \\
(0,030)\end{array}$ & $\begin{array}{c}0,130 \\
(0,031)\end{array}$ & $\begin{array}{c}0,159 \\
(0,031)\end{array}$ \\
\hline Regime 2 & $\begin{array}{c}0,282 \\
(0,039)\end{array}$ & $\begin{array}{c}0,295 \\
(0,043)\end{array}$ & $\begin{array}{c}0,294 \\
(0,039)\end{array}$ & $\begin{array}{c}0,319 \\
(0,044)\end{array}$ & $\begin{array}{c}0,294 \\
(0,039)\end{array}$ & $\begin{array}{c}0,302 \\
(0,039)\end{array}$ \\
\hline
\end{tabular}

Lembrando que a elasticidade estimada é a combinação do repasse cambial aos preços de exportação menos o repasse cambial aos preços domésticos, e que as estimativas de repasse cambial aos preços ao atacado situam-se em torno de 0,18, conforme os trabalhos de Nogueira et al. (2014) e Kannebley Júnior et al. (2016), é possível concluir que o repasse cambial aos preços de exportações deve se situar entre 0,16 e 0,18 . Isto é, um nível de repasse cambial bastante próximo de completo, que indica que os preços de exportações são fortemente influuenciados pelos preços praticados no mercado internacional e que seus efeitos devem ser pronunciados em termos de resultados comerciais no longo prazo. Essa influência se manifesta em ordem decrescente nos preços dos bens de capital, de consumo não duráveis, intermediários e de consumo duráveis.

Além de observarmos elasticidades de curto prazo também variam de acordo com a categoria de uso dos bens, observamos a existência de respostas distintas na margem entre os preços de exportação e domésticos em razão da direção da variação cambial. Em momentos de sobreapreciação cambial os exportadores adotam práticas de suavização dos preços a fim de evitar o encarecimento dos seus produtos no mercado externo, enquanto que em momentos de sobredepreciação cambial os exportadores repassam em maior intensidade a variação cambial, provavelmente, com o objetivo de incrementar sua parcela de mercado. Dada a intensa volatilidade da taxa nominal de câmbio no Brasil, e, portanto, a maior possibilidade de desalinhamentos cambiais, a previsão no curto prazo do comportamento dos preços de exportações e consequentes 
efeitos sobre a balança comercial tornam-se mais complexos e com impactos diferenciados.

\section{Referências Bibliográficas}

Barbieri, L. (2009), 'Panel unit root tests under cross-sectional dependence: an overview', Journal of Statistics: Advances in Theory and Applications 1(2), 117-158.

Barroso, J. B. R. B. (2012), Pricing-to-market by Brazilian exporters: a panel cointegration approach, Technical report, Banco Central do Brasil.

Byrne, J. P., Kortava, E. \& MacDonald, R. (2013), 'A new approach to tests of pricing-to-market', Journal of International Money and Finance 32, 654-667.

Correa, A. L. (2012), 'Taxa de câmbio e preços de exportação no Brasil: avaliação empírica dos coeficientes de pass-through setoriais', Economia e Sociedade pp. 61-99.

Da Silva Correa, A., Petrassi, M. B. S., Santos, R. \& et al (2016), Price-setting behavior in Brazil: survey evidence, Technical report, Banco Central do Brasil.

Ferreira, A. \& Sansó, A. (1999), Exchange rate pass-through: the case of Brazilian exports of manufactures, in 'XII World Congress of International Economics Association', Buenos Aires.

Froot, K. A. \& Klemperer, P. D. (1989), 'Exchange rate pass-through when market share matters', The American Economic Review .

Gagnon, J. E. \& Knetter, M. M. (1995), 'Markup adjustment and exchange rate GS fluctuations: evidence from panel data on automobile exports', Journal of International Money and Finance 14(2), 289-310.

Gil-Pareja, S. (1995), 'Exchange rates and European countries' export prices: an empirical test for asymmetries in pricing to market behavior', Journal of International Money and Finance 136(1), 1-23.

Hamilton, J. D. (1994), Time Series Analysis, Vol. 2, Princeton University Press.

Hansen, B. E. (1999), 'Threshold effects in non-dynamic panels: estimation, testing, and inference', Journal of Econometrics 93(2), 345-368.

URL: $h t t p: / / w w w . s c i e n c e d i r e c t . c o m / s c i e n c e / a r t i c l e / p i i / S 0304407699000251$

Kannebley Júnior, S. (2000), 'Exchange rate pass-through: uma análise setorial para as exportações brasileiras (1984-1997)', Economia Aplicada $4(3), 435-463$.

Kannebley Júnior, S., Reis, G. H. A. d. \& Toneto Junior, R. (2016), 'Exchange rate pass-through in the Brazilian manufacturing industry', Economia e Sociedade 25(1), 25-50.

Knetter, M. M. (1989), 'Price discrimination by us and German exporters', The American Economic Review pp. 198-210. 
Knetter, M. M. (1994), 'Is export price adjustment asymmetric? evaluating the market share and marketing bottlenecks hypotheses', Journal of International Money and Finance 13(1), 55-70.

Krugman, P. (1986), 'Pricing to market when the exchange rate changes'.

URL: http://www.nber.org/papers/w1926

Maddala, G. \& Wu, S. (1999), 'A comparative study of unit root tests with panel data and a new simple test', Oxford Bulletin of Economics and Statistics 61(S1), 631-652.

Marston, R. C. (1990), 'Pricing to market in Japanese manufacturing', Journal of International Economics 29(3), 217-236.

Nogueira, V. A. d., Mori, R. \& Marçal, E. (2014), Transmissão da variação cambial para as taxas de inflação no Brasil: estimação do pass-through através de modelos de vetores autorregressivos estruturais com correção de erros, Technical report, ANPEC-Associação Nacional dos Centros de Pós-graduação em Economia [Brazilian Association of Graduate Programs in Economics].

Pedroni, P. (2001a), 'Purchasing power parity tests in cointegrated panels', The Review of Economics and Statistics 83, 727-731.

Pedroni, P. (2001b), 'Purchasing power parity tests in cointegrated panels', The Review of Economics and Statistics 83(4), 727-731.

Pesaran, M. H. (2007), 'A simple panel unit root test in the presence of crosssection dependence', Journal of Applied Econometrics 22(2), 265-312.

Pesaran, M. H., Shin, Y. \& Smith, R. P. (1999), 'Pooled mean group estimation of dynamic heterogeneous panels', Journal of the American Statistical Association 94(446), 621-634.

Pesaran, M. H. \& Smith, R. (1995), 'Estimating long-run relationships from dynamic heterogeneous panels', Journal of Econometrics 68(1), 79-113.

Westerlund, J. (2007), 'Testing for error correction in panel data', Oxford Bulletin of Economics and Statistics 69(6), 709-748. 
